\title{
Left atrial myxoma diagnosed by echocardiography, with observations on tumour movement
}

\author{
Nigel M. Bass and Geoffrey P. Sharratt \\ From the Department of Cardiology, North Staffs Hospital Group, Stoke-on-Trent
}

The case is described of a 24-year-old woman who had a left atrial myxoma which mimicked mitral stenosis, and was diagnosed by echocardiography. The place of echocardiography in the diagnosis of this lesion is discussed. The early diastolic sound and accentuated first heart sound of atrial myxoma is shown to be associated with tumour movement.

Left atrial myxomas commonly mimic mitral stenosis and are found in approximately $I$ in every 200 to 400 operations for mitral valve obstruction (Greenwood, 1968). Echocardiography is a simple and safe procedure that gives apparently specific appearances for mobile atrial myxomas and can be useful as a screening test in cases of mitral valve disease. We report a case of left atrial myxoma diagnosed by ultrasound and we comment on the nature of tumour movement.

\section{Case report}

A 23-year-old Caucasian woman presented with a I2month history of obvious progressive exertional dyspnoea and orthopnoea. She had had four episodes of paroxysmal nocturnal dyspnoea. For two months she had had generalized muscular aches and sudden episodes of sweating, not associated with fever. No syncope or embolic episodes had occurred.

On examination she was afebrile. She was in sinus rhythm and the peripheral pulses were normal, blood pressure $130 / 60 \mathrm{mmHg}$. The jugular venous pressure was raised to $5 \mathrm{~cm}$ above the sternal angle with prominent $A$ waves. The left ventricular impulse was normal but a pronounced right ventricular lift was palpable. The first heart sound was very loud, the second heart sound had physiological splitting, and the pulmonary component was accentuated. There was a loud high-pitched early diastolic sound heard maximally at the lower left sternal edge. There were no diastolic murmurs. A grade 2/6 pansystolic murmur was present at the apex and left sternal border and there was no respiratory or positional variation of this murmur.

Investigations revealed an ESR of $8 \mathrm{~mm}$ in one hour (Westergren). The total plasma proteins and immunoglobulins were normal but protein electrophoresis showed a slight increase in $\alpha_{2}$-globulins.
The chest $x$-ray showed slight cardiomegaly with prominence of the main pulmonary artery and left atrial appendage. The lung fields were considered to be normal.

The electrocardiogram showed sinus rhythm with left atrial enlargement and right ventricular hypertrophy.

Echocardiography was performed. Echograms of movement of the region of the anterior cusp of the mitral valve (Fig. Ia) showed that behind the anterior mitral cusp echo was a mass of horizontal echoes which represented the left atrial tumour. The tumour echoes are seen to move rapidly forwards in early diastole and project beyond the mitral valve into the left ventricle. The tumour echoes move back into the left atrium in systole.

Fig. Ic shows simultaneous recordings of the echocardiogram with the phonocardiogram and electrocardiogram. The maximum point of opening of the anterior cusp of the mitral valve (pt E) is followed $0.07 \mathrm{sec}$ later by a more anterior peak (pt $\mathrm{T}$ ) which represents the arrest of tumour movement in the left ventricle. This coincides with the early diastolic sound. The $S_{2}$ to early diastolic sound interval is 0.12 to 0.15 sec. $S_{1}$ is accentuated and prolonged, the interval QC is 0.14 to $0.16 \mathrm{sec}$.

Cardiac catheterization revealed a pulmonary artery pressure of $65 / 35 \mathrm{mmHg}$ and an indirect left atrial pressure of $35 \mathrm{mmHg}$ with $\mathrm{V}$ waves up to $60 \mathrm{mmHg}$ with a slow Y descent. A pulmonary arteriogram was performed in the right anterior oblique position and this confirmed the presence of a pedunculated left atrial tumour which moved into the left ventricle during diastole (Fig. 2).

Using cardiopulmonary bypass the left atrial myxoma was removed along with a cuff of atrial septum.

Six hours after operation the echocardiography was repeated and this showed normal movement of the anterior cusp of the mitral valve with complete lack of tumour echoes (Fig. Ib). Fig. Id shows simultaneous recordings of the mitral echo with the phonocardiogram 


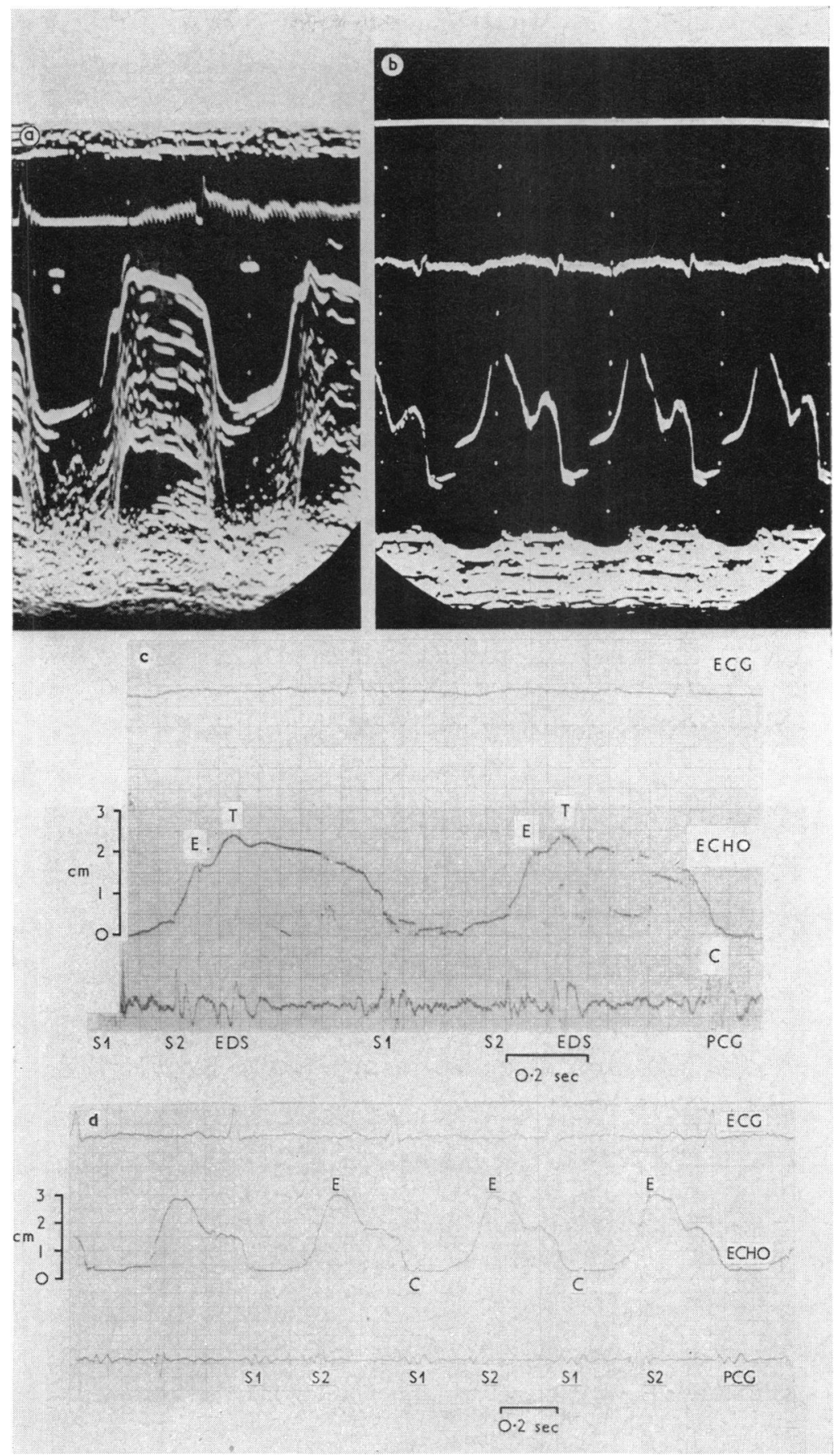

FIG. I a) Electrocardiogram above and echocardiogram of the region of the anterior cusp of the mitral valve below, before operation; $b$ ) electrocardiogram above and echocardiogram of the anterior cusp of the mitral valve below, after operation; c) electrocardiogram, time-motion echocardiogram recording of the region of the anterior cusp of the mitral valve, and phonocardiogram (PCG) recorded simultaneously, before operation; d) electrocardiogram, time-motion echocardiogram of the anterior cusp of the mitral valve, and phonocardiogram recorded simultaneously, after operation. 
1334 Bass and Sharratt

a)

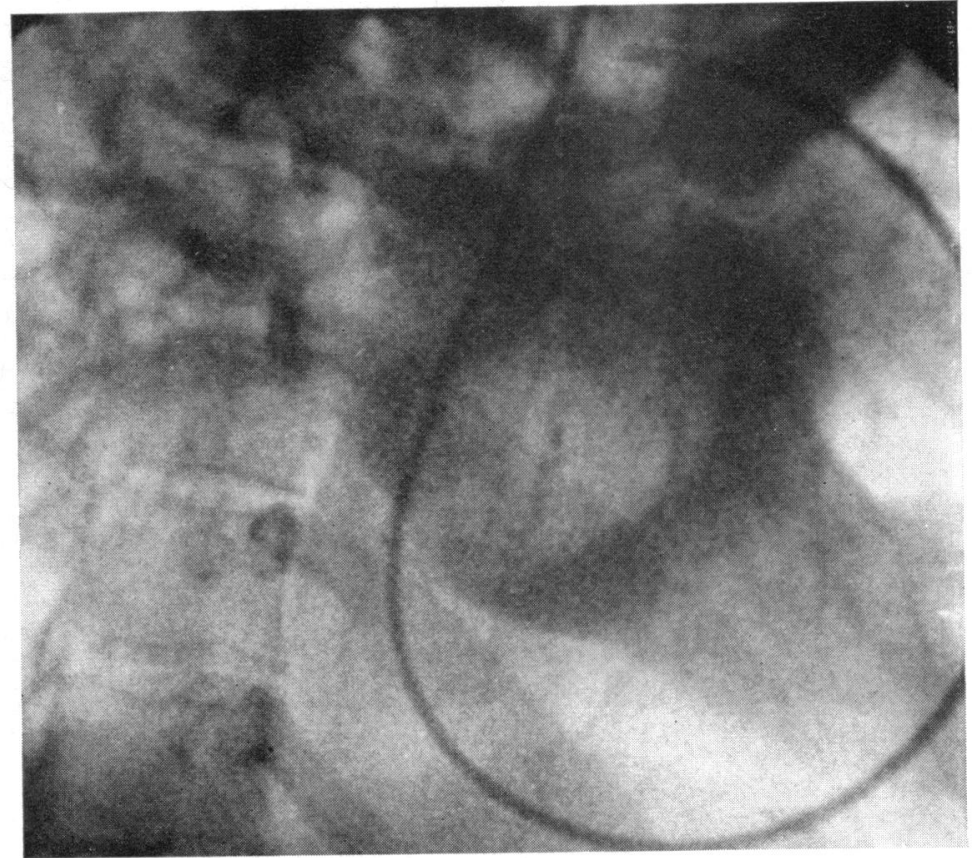

b)

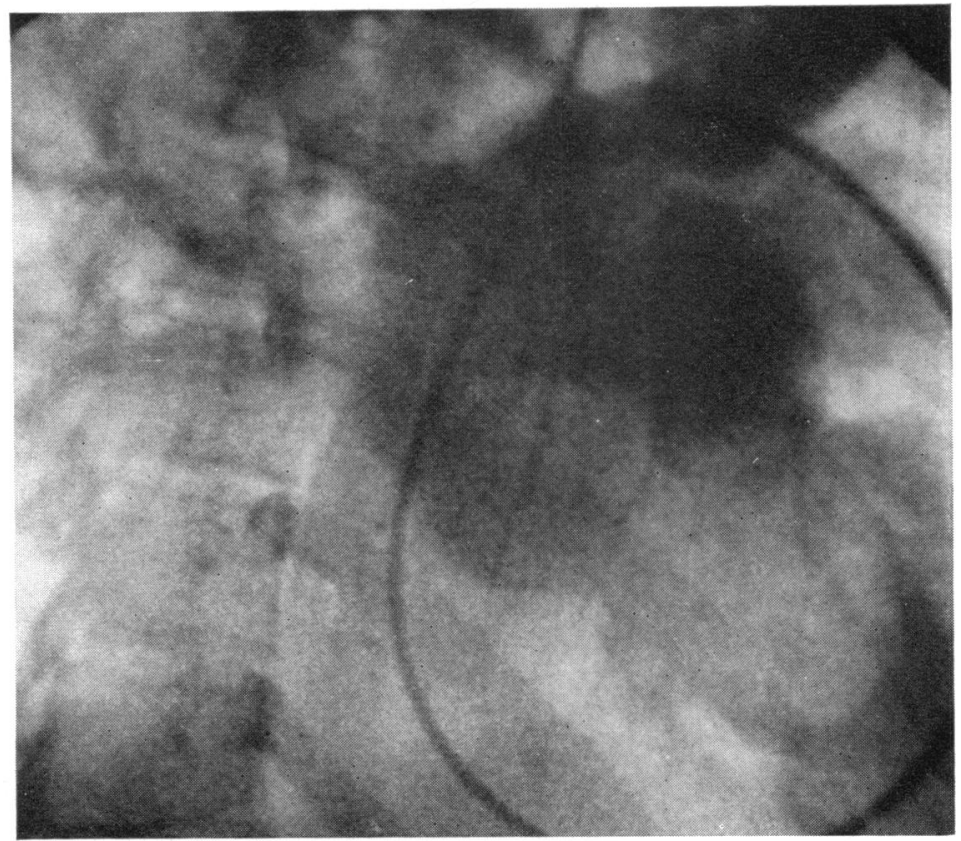

FIG. 2 Pulmonary arteriogram, right anterior oblique position, in the laevophase - a) ventricular systole with a filling defect in the left atrium; $b$ ) diastole with the filling defect in left ventricle. 
and electrocardiogram. The early diastolic sound has disappeared and the first heart sound is normal. The QC interval is now 0.10 sec.

The patient made an uneventful recovery. The pansystolic murmur was still present two months after operation, but by six months this was no longer heard. There is no echocardiographic evidence of recurrence and the patient is asymptomatic.

\section{Discussion}

Echocardiography of the anterior cusp of the mitral valve is a useful aid to the quantitative assessment of mitral stenosis (Segal, Likoff, and Kingsley, I966). In addition if echoes are seen behind the anterior cusp the presence of a left atrial thrombus or myxoma should be suspected, but many false negatives have been encountered (Tallury and DePasquale, I97I). If, however, these echoes are seen to move into the left ventricle in diastole, the diagnosis of left atrial myxoma is virtually certain (Nasser et al., I972).

The presence of an opening snap with a left atrial myxoma was first described by Lefcoe, Brien, and Manning (1957). Wassermil, Warkentin, and Ravin (I962) considered that this was due to the raised left atrial pressure. However, in view of the long $S_{2}$ to early diastolic sound gap, and in our case this was 0.12 to $0.15 \mathrm{sec}$, and the angiographic appearance of left atrial myxomas, the early diastolic sound is thought to be caused by tumour movement (Zitnik, Giuliani, and Burchell, I969). This case clearly shows that the early diastolic sound is produced at the time of arrest of movement of the tumour and could be either tensing of the tumour stalk or the tumour hitting the left ventricular wall.

The first heart sound has been noted to be accenuated and prolonged in patients with a left atrial myxoma (Wassermil et al., I962) and this was so in the case presented. Preoperatively the $\mathrm{QS}_{1}$ interval was $0.10 \mathrm{sec}$ at a heart rate of 75 a minute and postoperatively the $Q S_{1}$ interval was $0.07 \mathrm{sec}$ at a heart rate of 105 a minute. Point $C$ on the echo trace (Fig. Ic and d) is the most posterior position that the anterior cusp of the mitral valve reaches. The QC interval preoperatively was 0.14 to $0.16 \mathrm{sec}$ and postoperatively was $0 \cdot 10$ sec. We think that this represents delay in closure of the mitral valve be- cause of the time required for the tumour to move back into the left atrium, and that this movement forms part of the first heart sound which is thus accentuated and prolonged.

It has been stated that in the case of a left atrial myxoma the indirect left atrial pressure trace shows a rapid $\mathrm{Y}$ descent, thus distinguishing it from mitral stenosis (Pitt et al., 1967). However, in this case the $\mathrm{Y}$ descent was slow and the reason for this is unknown.

We have now seen a second case of left atrial myxoma and the echocardiographic appearances were identical with those shown above.

We wish to thank Dr. J. P. P. Stock and Mr. J. M. Sanderson for permission to publish this case, Dr. Peter Carson for his helpful advice, and Dr. Mackinnon for referring the second case to us.

We would also like to thank Mrs. L. Barker, of the Heart Research Fund, for the money to purchase the Echoline 20.

\section{References}

Greenwood, W. F. (1968). Profile of atrial myxoma. American fournal of Cardiology, 21, 367.

Lefcoe, N. M., Brien, F. S., and Manning, G. W .(1957). An opening snap recorded in a case of tumor of the left atrium. New England fournal of Medicine, $257,178$.

Nasser, W. K., Davis, R. H., Dillon, J. C., Tavel, M. E., Helmen, C. H., Feigenbaum, H., and Fisch, C. (1972). Atrial myxoma. II: Phonocardiographic, echocardiographic, hemodynamic and angiographic features in nine cases. American Heart fournal, 83, 810 .

Pitt, A., Pitt, B., Schaefer, J., and Criley, J. M. (1967). Myxoma of the left atrium: haemodynamic and phonocardiographic consequences of sudden tumor movement. Circulation, 36, 408.

Segal, B. L., Likoff, W., and Kingsley, B. (1966). Echocardiography: clinical application in mitral stenosis. fournal of the American Medical Association, 195, 16r.

Tallury, V. K., and DePasquale, N. P. (1971). Ultrasound cardiography in the diagnosis of left atrial thrombus. Chest, 59, 501.

Wassermil, M., Warkentin, D. L., and Ravin, A. (1962). Myxoma of the left atrium: phonocardiographic study of three cases. Circulation, 25, 50.

Zitnik, R. S., Giuliani, E. R., and Burchell, H. B. (1969). Left atrial myxoma: phonocardiographic clues to diagnosis. American fournal of Cardiology, 23, 588.

Requests for reprints to Dr. G. P. Sharratt, Cardiac Department, City General Hospital, Stoke-on-Trent ST4 6QG, Staffs. 